\title{
Effect of minor Co additions on the crystallization and magnetic properties of $\mathrm{Fe}(\mathrm{Co}) \mathrm{NbBCu}$ alloys
}

\author{
J. Torrens-Serra $^{1, *}$, P. Bruna ${ }^{2}$, S. Roth $^{3}$, J. Rodriguez-Viejo $^{1,4}$, M.T. Clavaguera-Mora ${ }^{1}$ \\ ${ }^{1}$ Grup de Nanomaterials i Microsistemes. Departament de Física. Universitat Autònoma de \\ Barcelona. Edifici Cc, 08193 Bellaterra. Spain \\ ${ }^{2}$ Departament de Física Aplicada, EPSC, Centre de Recerca en Nanoenginyeria, Universitat \\ Politècnica de Catalunya, Avda. del Canal Olímpic 15, 08860 Castelldefels, Spain \\ ${ }^{3}$ IFW-Dresden. Institut für Metallische Werkstoffe. Helmholtzstraße 20, Dresden, D-01069, \\ Germany \\ ${ }^{4 c}$ MATGAS Research Centre, UAB campus, 01893 Bellaterra, Spain.
}

\begin{abstract}
The effect of partial replacement of Fe by Co (up to $8 \%$ ) on thermal stability, structure and magnetic properties of $\mathrm{FeNbBCu}$ alloys has been explored in this paper. The results indicate that Co reduces the stability against crystallization of the amorphous alloy and stabilizes the nanocrystalline phase prior to the further precipitation of metastable boride phases. Transmission Mössbauer spectroscopy reveals differences in the hyperfine interactions between the alloys: Co raises the mean hyperfine field of the amorphous state and differences in the nanocrystalline bcc- $\mathrm{Fe}(\mathrm{Co})$ environments between the alloys occur depending on the amount of Co near-neighbours in the bcc-Fe structure. The addition of Co has also a notable effect on the magnetic properties of both amorphous and nanocrystalline alloys increasing the Curie temperature, which shows a linear dependence with the Co composition, and the saturation polarization.
\end{abstract}

\footnotetext{
${ }^{*}$ Corresponding author. Tel: +34935811481; fax: +34935812155. E-mail address: joan@vega.uab.es
} 


\section{Introduction}

Some Fe-based nanocrystalline alloys with selected overall composition, called often metal/amorphous nanocomposites, show excellent soft magnetic properties. They are two phase materials derived by partial crystallization of amorphous precursors resulting in nanocrystalline grains of a bcc-Fe phase consuming $20-70 \%$ of the total volume dispersed in an amorphous matrix. The patented Fe-TM-B-Cu alloys ( $\mathrm{TM}=\mathrm{Nb}, \mathrm{Zr}, \mathrm{Hf}$ ) have tradename Nanoperm and present very high saturation polarization and permeability and low magnetostriction [1-5]. The origin of ferromagnetism in this kind of systems comes from the exchange coupling of the bcc-Fe nanograins through the ferromagnetic residual matrix. The low coercivity is well described by the Random Anisotropy Model [6]. The magnetic properties are very sensitive to the composition changes so the amount of every element in the alloy affects both the values of polarization and the Curie temperature. Lots of efforts in order to enhance the magnetic properties have been done in these kinds of alloys. The most successful was the addition of Cobalt forming a new type of alloys called Hitperm [7]. The advantage of this FeCo-based alloy is a higher Curie temperature which makes this material suitable for high temperature application although several studies show not as good soft magnetic behaviour than for Co-free alloys. Also the increase of saturation induction in $\mathrm{FeCo}$ alloys present a maximum at about $35 \%$ of Co $[4,8,9]$. Nevertheless cobalt is a metal much more expensive than Fe. So a compromise should be reached in between the material improvement and the costs.

The production of the amorphous precursors of the nanocrystalline soft magnetic materials requires high cooling rates and they can only be produced in ribbon form which is not the most suitable shape for applications. Recently, alloys with higher glass forming ability due to the addition of higher amounts of glass formers such as boron have been explored [10]. However, in some cases the primary crystallization of undesired iron borides was observed which suppress the superior soft magnetic properties of the nanocrystalline samples. The 
limiting composition that separates the formation of bcc-Fe grains from borides was found to be $15 \%$ of $\mathrm{B}$ in alloys with $\mathrm{Nb}$ content of $10 \%$ at. The compositional dependence of properties in these high boron content alloys has been studied in previous works [11]. In this paper we examine the thermal stability, microstructural evolution and magnetic properties of the $\mathrm{Fe}_{77} \mathrm{Nb}_{7} \mathrm{~B}_{15} \mathrm{Cu}_{1}$ alloys with substitution of a low amount of $\mathrm{Fe}$ by $\mathrm{Co}$ (up to $8 \%$ ).

\section{Experimental procedure}

Master alloys of $\mathrm{Fe}_{77-\mathrm{x}} \mathrm{Co}_{\mathrm{x}} \mathrm{Nb}_{7} \mathrm{~B}_{15} \mathrm{Cu}_{1}(\mathrm{x}=0,2,4,8)$ were produced by arc melting under argon atmosphere from high purity materials $\mathrm{Fe}, \mathrm{FeB}, \mathrm{Co}, \mathrm{Nb}, \mathrm{Cu}$. Amorphous ribbons were prepared by a single-roller melt spinning technique on a copper wheel in inert Ar atmosphere. The as-quenched and annealed ribbons were inspected by x-ray diffraction (XRD) using $\mathrm{CoK} \alpha$ radiation $(\lambda=1.7888 \AA)$ in Bragg-Brentano geometry. The thermal stability was determined by differential scanning calorimetry (DSC) using a NETZSCH-DSC404 calorimeter at $10 \mathrm{~K} / \mathrm{min}$ under argon atmosphere. The kinetics of crystallization was studied for different heating rates using a Perkin-Elmer DSC7. A second scan has been always performed in order to subtract a baseline. The saturation magnetization was determined using a Lakeshore 735 VSM at constant temperature of $298 \mathrm{~K}$ using a maximum applied field of 1.5 T. The saturation polarization $\left(J_{s}\right)$ was calculated from the saturation magnetization and the theoretical density of the alloy. Thermomagnetic measurements were performed using a Faraday thermobalance with a field of $0.55 \mathrm{~T}$. The Curie temperature $\left(T_{c}\right)$ was determined by fitting $M(T)$ curves to $M(T)=M_{0}\left(1-T / T_{c}\right)^{0.36}$ [6]. Coercivity was determined using a Foersters Koerzimat in an applied field of $200 \mathrm{kA} / \mathrm{m}$. Transmission Mössbauer spectra (TMS) were obtained using a conventional constant acceleration spectrometer with a $25 \mathrm{mCi}$ source of ${ }^{57} \mathrm{Co}$ in Rh matrix. Experimental spectra were fitted with Brand's NORMOS program [12], considering for the amorphous phase one histogram magnetic hyperfine-field distribution with linear correlation between the isomer shift and the magnetic field and for the crystalline 
phases one singlet and several sextets. The isomer shift values are given relative to room temperature bcc-Fe.

\section{Results and discussion}

\subsection{Thermal stability}

The DSC scans performed at $10 \mathrm{~K} /$ min for the $\mathrm{Fe}_{77-\mathrm{x}} \mathrm{Co}_{\mathrm{x}} \mathrm{Nb}_{7} \mathrm{~B}_{15} \mathrm{Cu}_{1}(\mathrm{x}=0,2,4,8)$ studied alloys - named from now on $\mathrm{Fe} 77, \mathrm{Fe} 75 \mathrm{Co} 2, \mathrm{Fe} 73 \mathrm{Co} 4$ and $\mathrm{Fe} 69 \mathrm{Co} 8-$ are presented in Figure 1 in the range $700-1100 \mathrm{~K}$.

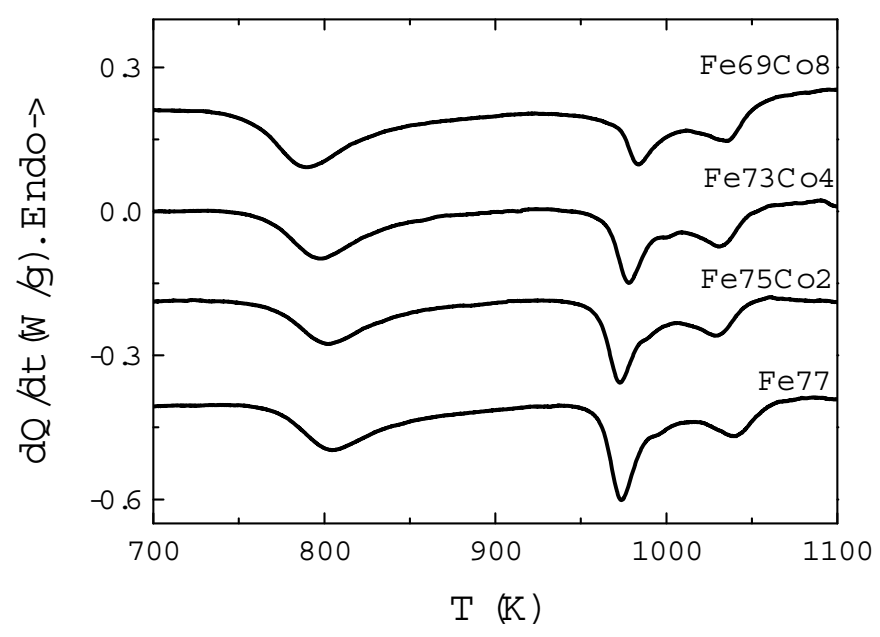

Figure 1

All four alloys show three different exothermic calorimetric events in this temperature interval. No shift in the baseline, indicative of a glass transition, is observed previous to the primary crystallization peak. This peak extends over about $70 \mathrm{~K}$ and is followed by a stable range of about $60 \mathrm{~K}$ of the nanocrystalline alloy preceding the next calorimetric peak. The characteristic temperatures as well as the enthalpy of primary crystallization are listed in Table 1. The onset temperature of the first peak $\left(T_{\mathrm{x} 1}\right)$ decreases with the partial replacement of Fe by Co, from 774 to $756 \mathrm{~K}$. On the contrary, the second exothermic peak temperature $\left(T_{\mathrm{p} 2}\right)$ increases from 972 to $984 \mathrm{~K}$ indicating a wider stable range of the nanocrystalline phase with 
the Co addition. A similar behaviour has been reported for $\mathrm{Cu}$ free $\mathrm{Fe}_{85-\mathrm{x}} \mathrm{Co}_{\mathrm{x}} \mathrm{Nb}_{7} \mathrm{~B}_{8}$ with $\mathrm{x}=$ 2,5 but the nanocrystalline material's stability decreases again when increasing $\mathrm{x}$ up to 30 at $\%$ [13]. While the nanocrystallization enthalpy rises with Co content, the crystallization enthalpy of the second peak decreases, as it can be inferred from Figure 1. In samples Fe77, Fe75Co2 and $\mathrm{Fe} 73 \mathrm{Co} 4$ a fourth peak is found at about $1182 \mathrm{~K}$ [14] whereas in the Fe69Co8 it is not distinguished in the DSC scan at this heating rate but could probably be seen at heating rates higher than $10 \mathrm{~K} / \mathrm{min}$. The apparent activation energy of nanocrystallization $\left(E_{a}\right)$ was calculated using the Kissinger method [15] from calorimetric scans at different heating rates. For Co-free alloy $E_{a}=5.8 \mathrm{eV}$ but it decreases to about 5.4 with cobalt addition (Table 1). Our results on thermal stability follow the trend reported by Blazquez et al. [16] in $\mathrm{Fe}_{78-}$ ${ }_{x} \mathrm{Co}_{\mathrm{x}} \mathrm{Nb}_{6} \mathrm{~B}_{15} \mathrm{Cu}_{1}$ (with $\mathrm{x}=18,39$ and 60) alloys, as shown in Figure 2.

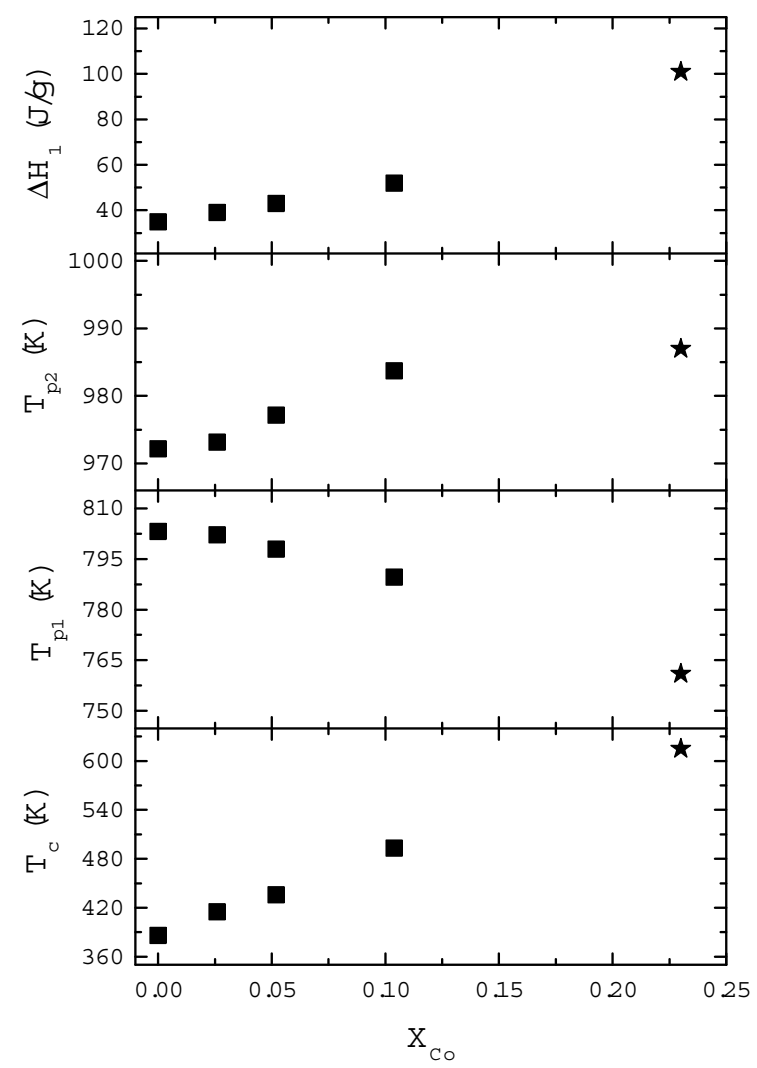

Figure 2 
However these authors found activation energy values around $3.6 \mathrm{eV}$, much lower than our results, around $5.4 \mathrm{eV}$, quite independent of the Co content. Other authors [8] found in $\mathrm{Fe}_{86} \mathrm{Zr}_{7} \mathrm{~B}_{6} \mathrm{Cu}_{1} \mathrm{Co}_{\mathrm{x}}$ alloys (with $\mathrm{x} \leq 20$ ) a decrease on both primary and secondary crystallization peak temperatures with increasing the Co content. The kinetics of nanocrystallization has been studied for the Fe77 and Fe69Co8 alloys, the two extreme compositions. The master curve method (MCM) has been applied to determine the experimental kinetic function $P(x)$ from which the Avrami exponent $n$ is determined by comparison with the Avrami equation.

$$
P(x)=\frac{P_{0}[-\ln (1-x)]^{\frac{1-n}{n}}}{n(1-x)}
$$

The procedure also gives the apparent activation energy. A comprehensive explanation and discussion of this method is published elsewhere [17,18]. The Avrami exponent has been determined in the beginning of the transformation, as presented in figure $3,1 \%<\alpha<8 \%$ and gives $n=0.78$ and $E_{a}=5.7 \mathrm{eV}$ for Fe77, and $n=0.85$ and $E_{a}=5.1 \mathrm{eV}$ for Fe69Co8. The values of $E_{a}$ are similar to those found using Kissinger method. The parameter $n$ is very similar for both alloys and this fact indicates that the addition of Co does not alter the mechanisms controlling the primary crystallization. Moreover, similar values were obtained in comparable alloys using different analysis procedures. Such low values of Avrami exponent can not be directly interpreted in terms of the KJMA theory. Some authors have attributed them to a decreasing nucleation rate and instantaneous growth $[19,20]$. The high activation energy values and the small diameter of the nanocrystals support the interpretation that nucleation dominates the crystallization process. 


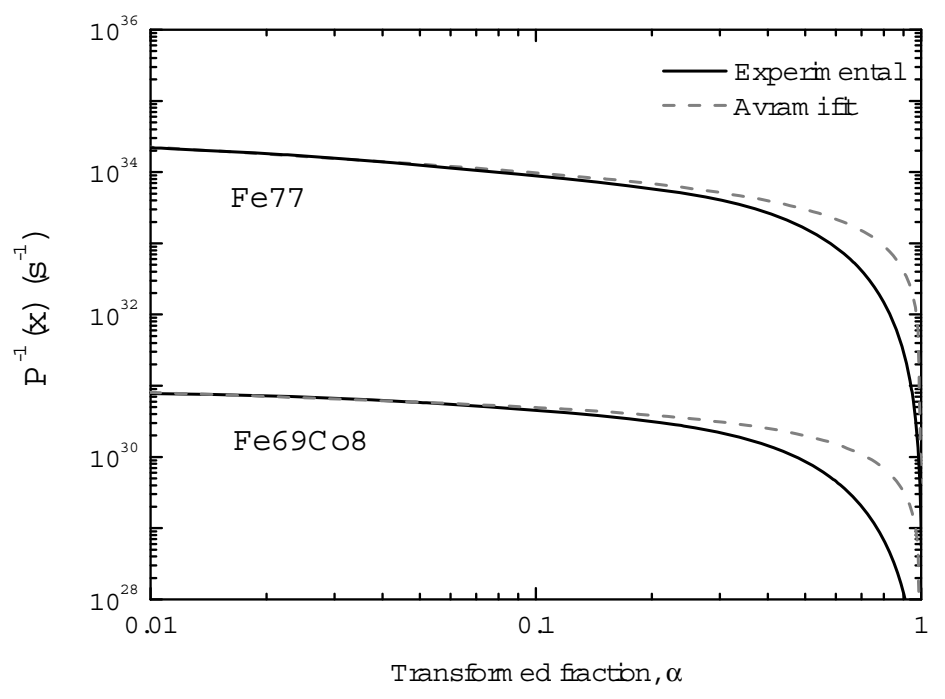

Figure 3

\subsection{Microstructural evolution}

The amorphous nature of the as-quenched alloys was checked by XRD and TMS. After heating up to $893 \mathrm{~K}$ (temperature well above the end of the primary crystallization) and then cooling down to room temperature, the XRD patterns of the alloys show the Bragg peaks corresponding to the bcc- $\mathrm{Fe}(\mathrm{Co})$ phase (Figure 4).

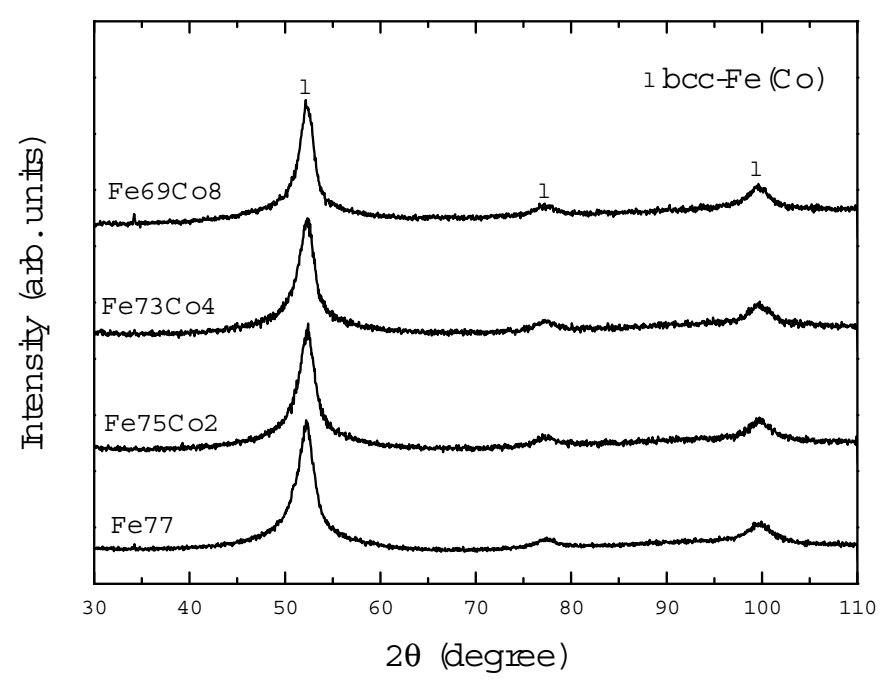

Figure 4. 
The first Bragg peak (110) was used to estimate the mean grain size, $<\mathrm{D}>$, using the Langford method [21]. The results indicate $\langle D>$ values slightly increase from $3.8 \mathrm{~nm}$ for Fe77 to 5.3 $\mathrm{nm}$ for Fe69Co8. These small values agree with the fact that growth is hindered. Values for $<D>$ around $5 \mathrm{~nm}$ were obtained for alloys with higher Co content by transmission electron microscopy (TEM) i.e., $\mathrm{Fe}_{78-\mathrm{x}} \mathrm{Co}_{\mathrm{x}} \mathrm{Nb}_{6} \mathrm{~B}_{15} \mathrm{Cu}_{1}$ in the range $18 \leq x \leq 60$ [16]. The X-ray diffraction patterns after heating the nanocrystalline material up to higher temperatures (1100 $\mathrm{K}$ and $1273 \mathrm{~K}$ ) show the precipitation of the same phases as in the Co-free alloy [22]. The TMS spectra for the as-quenched ribbons exhibit the typical distribution for disordered ferromagnetic materials and therefore they have been fitted using a unique histogram magnetic hyperfine-field distribution (figure 5).
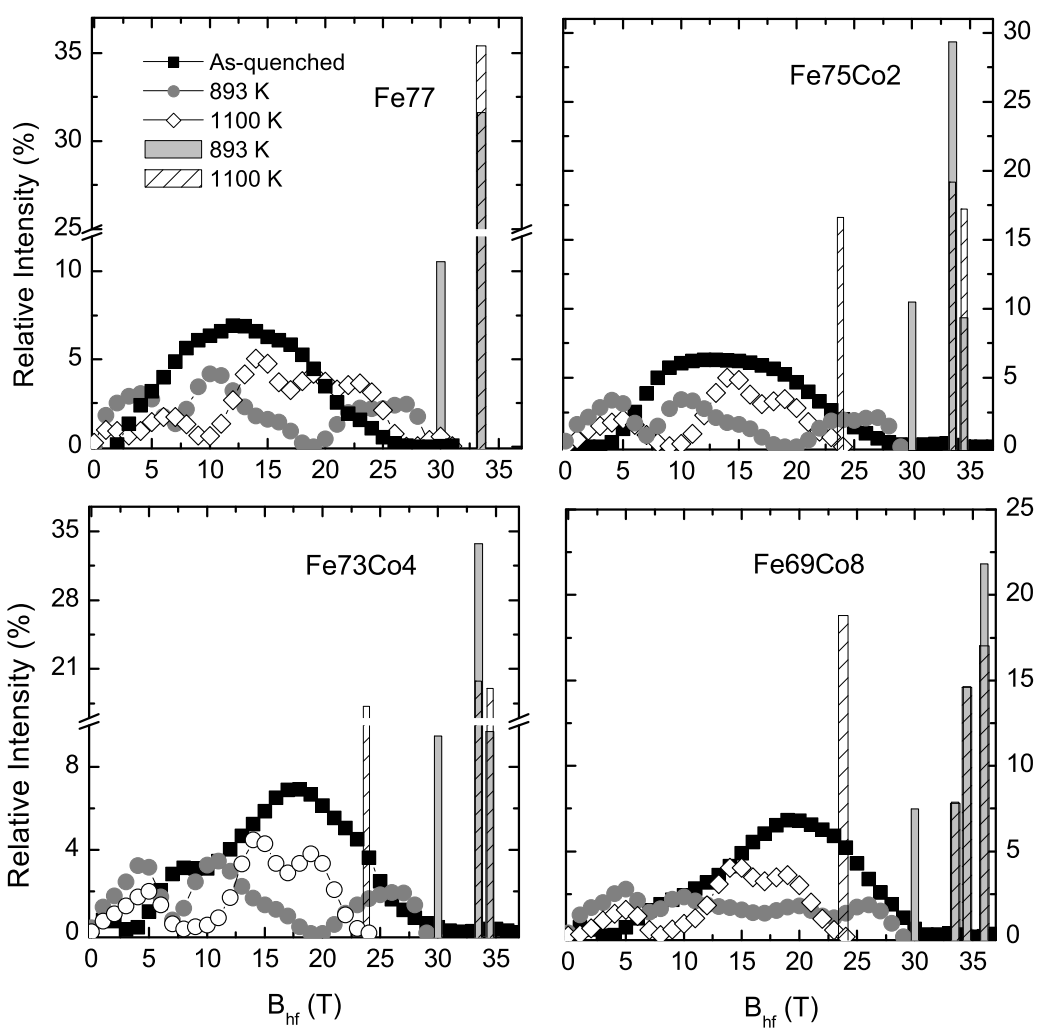

Figure 5 
It can be observed how the mean hyperfine field of the distribution increases with the Co content of the ribbons as it goes from 13.4 (1) $\mathrm{T}$ for Fe77 to 18.4 (5) $\mathrm{T}$ for Fe69Co8 (see Table 2). After the primary crystallization, the spectra show the presence of bcc-Fe(Co) crystals embedded into the amorphous matrix. This crystalline phase has been fitted with one, two or three sextets depending on the Co concentration. For Fe77 only one sextet (hyperfine field, $B_{\mathrm{hf}}=33.5 \mathrm{~T}$ ) has been used corresponding to a pure bcc-Fe phase, whereas for Fe $75 \mathrm{Co} 2$ and $\mathrm{Fe} 73 \mathrm{Co} 4$, two sextets are used accounting for, respectively, pure bcc-Fe and bcc- $\mathrm{Fe}(\mathrm{Co})$, with $1 / 8$ Co nearest-neighbours $(n-n)\left(B_{\mathrm{hf}}=34.5 \mathrm{~T}\right)$. Finally for the ribbon with higher Co content, Fe69Co8, a third sextet is used for the fraction of bcc-Fe with $2 / 8 \mathrm{Co} n-\mathrm{n}\left(B_{\mathrm{hf}}=35.5\right.$ $\mathrm{T})$. The atomic percentage of $\mathrm{Fe}$ in the nanocrystalline bcc- $\mathrm{Fe}(\mathrm{Co})$ phase calculated from TMS is shown in Figure 6a. The results indicate a higher transformed fraction in Fe73Co4 and Fe69Co8 alloys than in Co-free sample (from $~ 32 \%$ in Fe 77 to $\sim 44 \%$ in Fe69Co8) related to the higher mean crystal size estimated by XRD and the enhancement in the nanocrystallization enthalpy. Also, in figure $6 \mathrm{~b}$, the contribution of the different bcc-Fe(Co) environments as a function of the composition is presented. The sextet due to $8 \mathrm{Fe} n-n$ contribution decreases at expenses of the 7 and 6 Fe n-n higher field sextets in Fe69Co8 alloy. Moreover, in all the alloy compositions an extra sextet with a hyperfine field of $30 \mathrm{~T}$ is introduced to account for regions structurally close to the bcc-Fe. These regions are often ascribed to: $i)$ bcc- $\mathrm{Fe}(\mathrm{Co})$ with some interstitial boron; $i i)$ the interface zone situated at the crystal grain's surface; or iii) the region ahead of the interface where the $\mathrm{Nb}$ and $\mathrm{B}$ have segregated during the nanocrystallization process [23-26]. The hyperfine field distribution of the amorphous remnant after the first crystallization presents two different regions, one with $B_{\mathrm{hf}}$ contributions above $20 \mathrm{~T}$ and another for $B_{\mathrm{hf}}<20 \mathrm{~T}$. The high-field region corresponds to local structures close to iron-borides while in the low-field region, the hyperfine distributions present two maxima, around $3 \mathrm{~T}$ and $10 \mathrm{~T}$. These two maxima may be associated to an amorphous structure $\mathrm{Nb}$-rich and $\mathrm{Nb}$-poor, respectively [22]. The hyperfine field distribution 
of the amorphous remnant in the four nanocrystalline alloy compositions present a very similar structure, except Fe69Co8, where the regions with $B_{\mathrm{hf}}$ above and below $20 \mathrm{~T}$ are not clearly differentiated, indicating a more homogenous disordered structure.
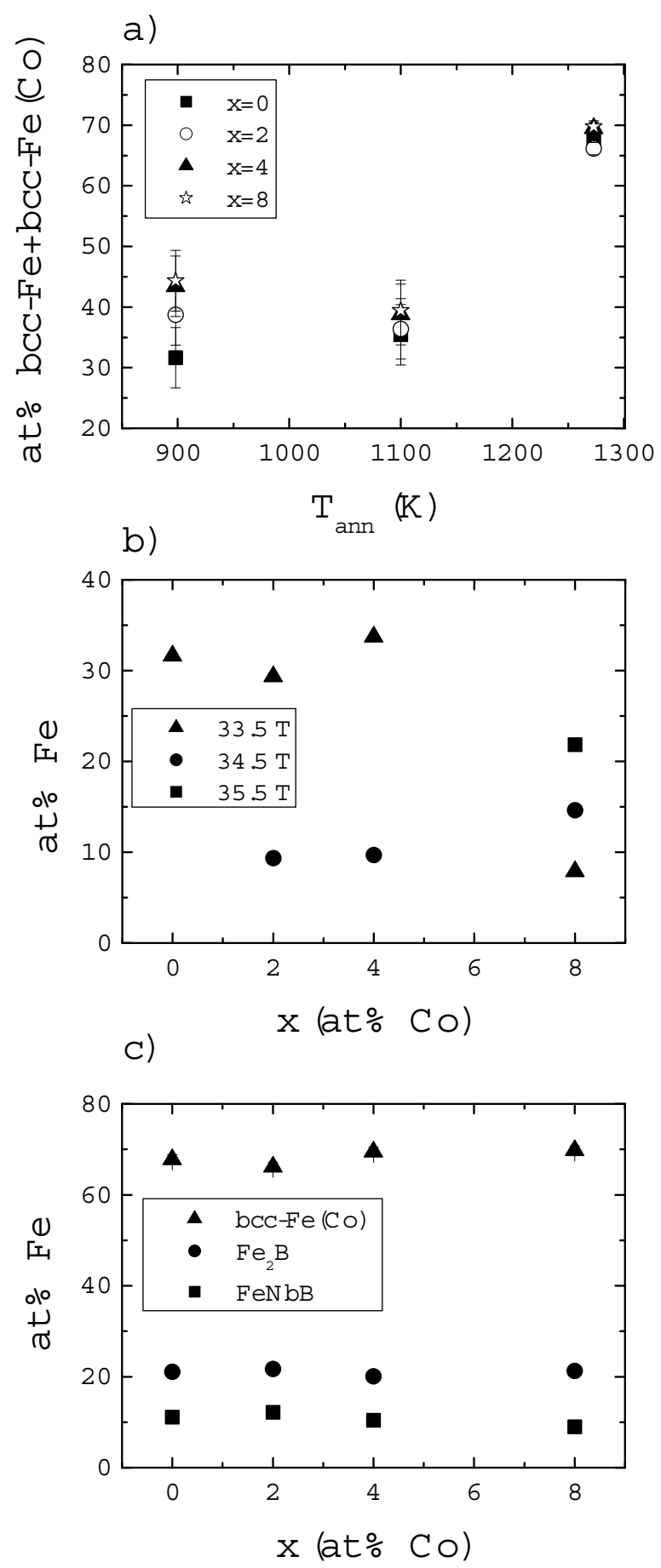

Figure 6 
After heating up to $1100 \mathrm{~K}$, the total amount of $\mathrm{Fe}$ in the bcc- $\mathrm{Fe}(\mathrm{Co})$ precipitates remains constant and close to 40 at\% (see Fig. 6a), only the relative amount of bcc-Fe(Co) environments changes, the $\mathrm{Fe}$ at $\%$ assigned to the $34.5 \mathrm{~T}$ sextet increases while that of pure bcc-Fe decreases in the $\mathrm{Fe} 75 \mathrm{Co} 2$ and $\mathrm{Fe} 73 \mathrm{Co} 4$ alloys. The $B_{\mathrm{hf}}=30 \mathrm{~T}$ sextet is no longer needed to fit the spectra, probably because the reduction of the disorder in the grain boundaries due to the easier diffusion at this temperature. Moreover, a new sextet corresponding to the o- $\mathrm{Fe}_{3} \mathrm{~B}$ phase with $B_{\mathrm{hf}}=23.8 \mathrm{~T}$, is needed to fit the spectra of the alloys that contain Co. This new phase is created from the high-field region of the amorphous remnant of the nanocrystalline alloys. That is, one effect of the Co addition is to favor the crystallization of the $\mathrm{Fe}_{3} \mathrm{~B}$ phase. In the Co-free alloy, although present, this phase can not be fitted with a sextet meaning that its presence is limited in contrast with the results of XRD where its peaks are perfectly defined. Furthermore, two new maxima appear in the hyperfine field distribution: the first one at $\sim 14 \mathrm{~T}$, resulting from a shift towards higher field values of the peak around $10 \mathrm{~T}$, that suggests atomic rearrangements that lead to the formation of low field regions from which $\mathrm{FeNbB}$ phase will crystallize in fully crystalline samples; and the second one at $\sim 18 \mathrm{~T}$, indicating a $\mathrm{Fe}_{23} \mathrm{~B}_{6}$-like atomic environment. Finally, after the last crystallization event, several crystalline phases are observed while the amorphous matrix has completely disappeared. Therefore the fits of all the alloys consist in a singlet for the paramagnetic $\mathrm{FeNbB}$ phase, one sextet for the stable $\mathrm{Fe}_{2} \mathrm{~B}$ boride and one, two or three sextets for the bcc- $\mathrm{Fe}(\mathrm{Co})$ phase in agreement with x-ray results [22]. The Fe at.\% for the different stable phases is the same for all the compositions (Fig 6c). It is important to stress that the sextets used to fit he total bcc- $\mathrm{Fe}(\mathrm{Co})$ phase in each of the alloy compositions have been selected to maintain the probability of having a bcc structure with $n$ Fe n-n atoms and (8-n) Co n-n atoms of an Fe atom following the procedure published in [26], except when this probability is less than $7 \%$. This probability is given by: 
$P=\frac{8 !}{(8-n) ! n !} Y_{F e}^{n} Y_{C o}^{8-n}$

with $Y_{F e}=\left(9 X_{F e}-1\right) / 8$ and $Y_{C o}=\left(9 X_{C o}\right) / 8$ are the concentration of atoms of Fe and Co providing that there's a central atom of Fe surrounded by $8 \mathrm{n}-\mathrm{n}$ and $X_{F e}$ and $X_{C o}$ are the concentration of iron and cobalt calculated normalizing the iron and cobalt content as if they were the only constituents of the alloy, see table 3.

The evolution of the bcc- $\mathrm{Fe}(\mathrm{Co})$ phase through all the thermal process shows that, for all the alloy compositions, its amount remains similar between the first and second crystallization event and it is only after the final event that the bcc- $\mathrm{Fe}(\mathrm{Co})$ phase reaches its greater extension, being of approximately $68 \%$ of the Fe content (Fig 5).

It is worth to note that the crystalline phase is still bcc-type and no transition to fcc is observed. The results reported by Muller [8] indicate that the precipitation of fcc-Co phase does not occur until higher Co percentages (above $86 \%$ ).

\subsection{Magnetic characterization}

The magnetization change with temperature of the amorphous alloy is plotted in figure 7 . The initial drop to a zero magnetization is associated to the ferromagnetic-paramagnetic transition of the amorphous phase. Afterwards an increase is observed corresponding to the nanocrystallization of the bcc- $\mathrm{Fe}(\mathrm{Co})$ which remains ferromagnetic until the experimental limit of the Faraday balance. 


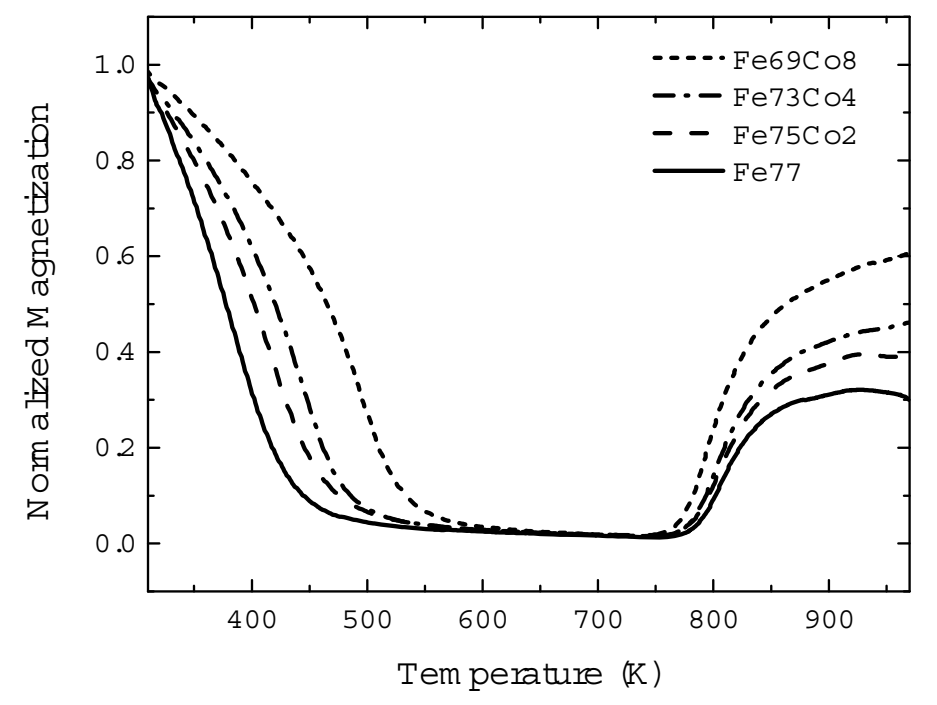

Figure 7

The Curie temperatures of the amorphous phase are listed in Table 2. It can be observed an enhancement of more than $100 \mathrm{~K}$ by only replacing $8 \%$ of Fe by Co. Such a large enhancement has also been recently reported in alloys with $10 \%$ of Co [27]. A second scan (not shown) reveals the behaviour of a two phase ferromagnetic material. A small step in the curve corresponding to the Curie temperature of the remnant amorphous phase is observed around $650 \mathrm{~K}$ while the nanocrystals are still ferromagnetic and exchange coupled up to higher temperatures. The average distance between nanocrystals, $d$, is calculated with the following relation [28]:

$d=<D>\left(\frac{1}{\sqrt[3]{p}}\right)-<D>$

with $<D>$ the average crystal size calculated from XRD and $p$ is the crystalline transformed volume fraction estimated by TMS. The results give values between $2.5 \mathrm{~nm}$ for Fe77 to 1.5 $\mathrm{nm}$ in Fe69Co8, typical values for fully nanocrystalline alloys.

The Curie temperature versus the relative amount of Co content is plotted in figure 2. A linear increase with cobalt is observed in this range of composition in accordance with reported data 
for $\mathrm{FeZrB}(\mathrm{Cu}) \mathrm{Co}[8,27]$ and $\mathrm{FeCoHfBCu}$ [29] alloys. The Curie temperature is parameterized as:

$T_{C}=386.2+1018.2 X_{C o}$

with $\mathrm{X}_{\mathrm{Co}}$ the normalized cobalt concentration. Similar linear relations have been recently reported in FeZrBCo alloys [27]. Moreover, comparison with data published by Blazquez et al. [16] in $\mathrm{Fe}_{60} \mathrm{Co}_{18} \mathrm{Nb}_{6} \mathrm{Cu}_{1}$ shows that this linearity may be extended over a larger compositional range. The Curie temperature depends on the mean magnetic moment or, in an alternative view, on the exchange interaction between atoms. The experimental behaviour is grounded in the increase of the interaction strength in Fe-Co when increasing Co content. It is worth mentioning that not only changes in the atom species affect the interaction strength but also changes in the interatomic distances in the disordered structure, especially in Fe-rich FeCo-based amorphous alloys. This has been successfully modelled taking asymmetric distribution of exchange interactions by Gallagher et al. [30]. The hysteresis loops for both the as-quenched and nanocrystalline alloys present the typical shape of a soft magnetic material. The magnetic polarization, listed in Table 2, has been calculated using the same procedure as in [22]. The addition of Co produces an increase of the saturation polarization in this compositional range. It is well known that alloying Co with Fe induces an increase of the polarization up to a composition of about $35 \%$ of $\mathrm{Co}$ in binary FeCo crystalline alloys [31]. Some studies observed a similar behaviour in $\mathrm{FeCoZrBCu}$ [8] and $\mathrm{FeCoHfBCu}[29]$ alloys both in amorphous and nanocrystalline state. In figure 8 , the saturation polarization $\left(J_{\mathrm{SA}}\right.$ for amorphous and $J_{\mathrm{SN}}$ for nanocrystalline) is plotted against the Co content. For the amorphous samples, the slope of the curve diminishes in the higher Co content alloys in good accordance with the measurements in other Nanoperm-type alloys [8,28] and in agreement with SlaterPauling curve predictions [4]. However, other studies in FeZrBCo showed linear dependence [27]. Both the saturation polarization and the average hyperfine field are a measurement of the local moment. The variation of the average hyperfine field for the amorphous alloy $\left(<B>_{\mathrm{A}}\right)$ 
can not be taken as linear. Our results of $\langle B\rangle_{\mathrm{A}}$ can be compared with those obtained for higher values of Co content since the tendency is a smoother slope in alloys with increasing Co content [16]. In the case of nanocrystalline samples not only the alloy chemistry is responsible of the magnetic properties but also structural factors as the grain size and the transformed fraction. The saturation polarization of the nanocrystalline materials increases with Co content due to two factors: (i) The increase in the mean magnetic moment (chemistry), and (ii) the larger transformed fraction and grain size when replacing iron by cobalt (see fig 6a). The values of coercivity (Table 2) are those typical for Nanoperm type alloys [4].

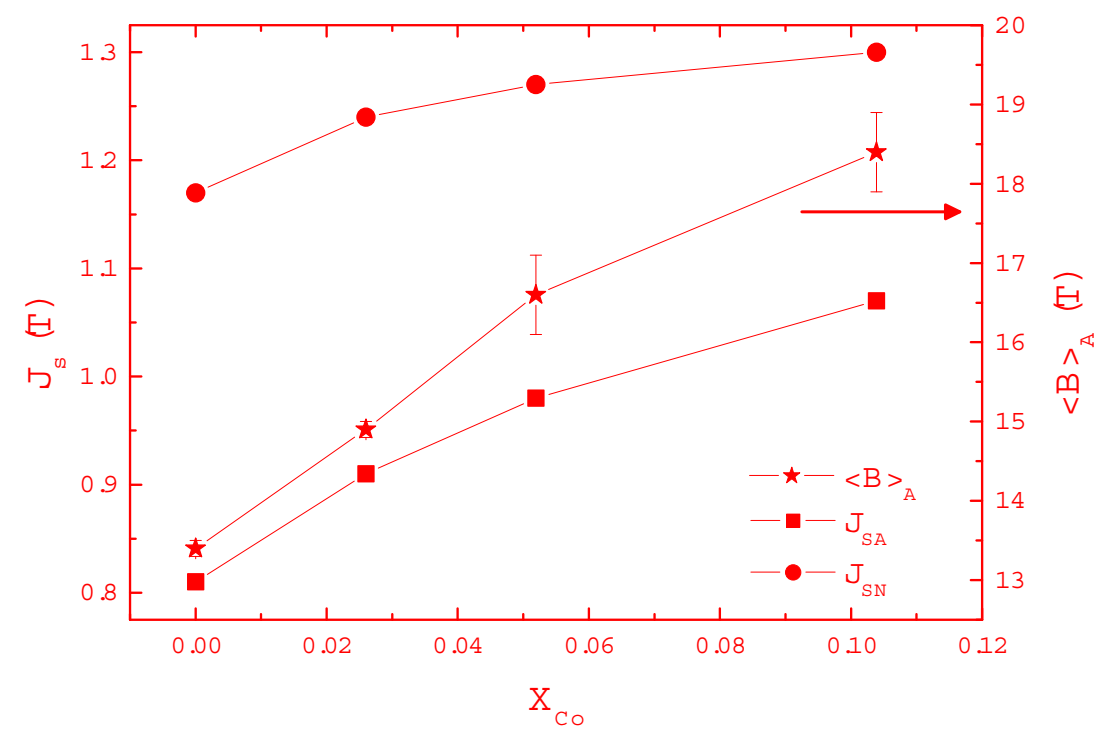

Figure 8

\section{Conclusions}

The devitrification of $\mathrm{Fe}_{77-\mathrm{x}} \mathrm{Co}_{\mathrm{x}} \mathrm{Nb}_{7} \mathrm{~B}_{15} \mathrm{Cu}_{1}(\mathrm{x}=0,2,4,8)$ amorphous alloys by heat treatment occurs through different exothermic events. The first one is the nanocrystallization of the bcc$\mathrm{Fe}(\mathrm{Co})$ phase in a residual amorphous matrix. The thermal stability of the initial amorphous 
ribbon is reduced by the partial replacement of Fe by Co whereas the amorphous remnant is stabilized leading to a wider temperature range of nanostructured material ready for operation. On the contrary, the addition of cobalt has no effect on the kinetics of nanocrystallization. The nanocrystalline bcc- $\mathrm{Fe}(\mathrm{Co})$ precipitates change with the cobalt content. In Fe77 there are no Co atoms and therefore pure bcc-Fe nanocrystals; in $\mathrm{Fe} 75 \mathrm{Co} 2$ and $\mathrm{Fe} 73 \mathrm{Co} 4$, alloys, pure bccFe nanocrystals coexist with Co substituting one nearest-neighbor of Fe and in Fe69Co8 alloy some bcc nanocrystals have two nearest-neighbor of Fe atom substituted by Co. The atomic arrangements of the amorphous remnant in the nanostructured material show two different kinds of environments: at high fields which will evolve to the metastable iron borides $\left(\mathrm{Fe}_{23} \mathrm{~B}_{6}\right.$ and $\mathrm{o}-\mathrm{Fe}_{3} \mathrm{~B}$ ) at the second exothermic event, and another corresponding to the creation of $\mathrm{Nb}$ rich zones bellow $10 \mathrm{~T}$. The metastable $\mathrm{o}-\mathrm{Fe}_{3} \mathrm{~B}$ is favored by the replacement of $\mathrm{Fe}$ by Co.

The four alloys have good soft magnetic properties in both amorphous and nanocrystalline states. The Curie temperature, the saturation polarization and the mean hyperfine field of the amorphous phase increase with Co: the first quantity follows a linear behavior up to concentrations $\sim 20 \%$ of Co, whereas the two other quantities show a decrease in the positive slope with Co concentration.

\section{Acknowledgments}

J. Torrens-Serra would like to thank Prof. L. Schultz and Dr. B. Rellinghaus for the opportunity to work in IFW-Dresden. This work was financed by the Spanish Ministry of Education and Science under projects MAT2007-61521 and MAT2007-60087, and by project 2009SGR01225 from the Direcció General de Recerca of the Generalitat of Catalonia. 


\section{References}

[1] A. Makino, T. Hatanai, A. Inoue, and T. Masumoto, Mater. Sci. Eng A226-228 (1997) 594-602.

[2] A. Makino, K. Suzuki, A. Inoue, and T. Masumoto, Mater. Sci. Eng. A179/180 (1994) $127-131$

[3] Y. Naitoh, T. Bitoh, T. Hatanai, A. Makino, A. Inoue, and T. Masumoto, Nanostructured Mater. 8 (1997) 987

[4] M.E. McHenry, M.A.Willard, and D.E. Laughlin, Prog. Mater. Sci. 44 (1999) 291-433

[5] K. Suzuki, J.M. Cardogan, V. Sahajwalla, A. Inoue, and T. Masumoto, Mater. Sci. Eng. A226-228 (1997) 554-558.

[6] G. Herzer, IEEE Trans. Magn, 25 (1989) 3327

[7] M.A.Willard, D.E. Laughlin, M.E. McHenry, D. Thoma, K. Sickafus, J. O. Cross, and V. G. Harris, J. Appl. Phys. 84 (1998) 6773-6777

[8] M. Müller, H. Grahl, N. Mattern, U. Kühn, and B. Schnell, J. Magn. Mag. Mater., 160 (1996) 284-286

[9] C. Gomez-Polo, P. Marín, L. Pascual, A. Hernando, and M. Vázquez, Phys Rev. B 65 (2001) 024433.

[10] J. Torrens-Serra, J. Rodríguez-Viejo, and M.T. Clavaguera-Mora, J. Non-Cryst. Solids 353 (2007) 842-844

[11] J. Torrens-Serra, P Bruna, S. Roth, J. Rodríguez-Viejo, and M.T. Clavaguera-Mora, Intermetallics, 10.1016/j.intermet.2009.12.006

[12] R. Brand, J. Lauer, and D. Herlach, J.Phys. F.: Metal. Phys. 14 (1984) 555

[13] Xingyu Mao, Feng Xu, Jianchen Tang, Wenli Gao, Shandong Li, and Youwei Du, J. Magn. Magn. Mater. 288 (2005) 106-110

[14] J. Torrens-Serra, S. Roth, J. Rodríguez-Viejo, and M.T. Clavaguera-Mora, J. Non-Cryst. Solids 354 (2008) 3858-3863 
[15] H. Kissinger, Anal. Chem. 29 (1957)1702

[16] J.S. Blazquez, J.M. Borrego, C.F. Conde, A.Conde, and J.M. Greneche, J. Phys.:

Condens. Matter 15 (2003) 3957-3968

[17] D. Jacovkis, Y. Xiao, J. Rodriguez-Viejo, M. T. Clavaguera-Mora, and N. Clavaguera, Acta Mater. 52 (2004) 2819.

[18] J. Torrens-Serra, J. Rodríguez-Viejo, and M. T. Clavaguera-Mora, Phys. Rev. B 76, (2007) 214111.

[19] J.S. Blazquez, C.F. Conde, and A. Conde, Acta Mater. 53 (2005) 2305-2311.

[20] J.S. Blázquez, V. Franco, C.F. Conde, M. Millán, and A. Conde, J. Non-Cryst. Solids 354 (2008) 3597-3605

[21] Th.H. Keijser, J.I. Langford, E.J. Mittemeijer, and A.B.P. Vogels. J. Appl. Crystallogr.15 (1982) 308 .

[22] J. Torrens-Serra, P Bruna, S. Roth, J. Rodríguez-Viejo, and M.T. Clavaguera-Mora, J. Phys. D: Appl. Phys. 42 (2009) 095010

[23] A.Slawska-Waniewska, and J.M.Greneche, Phys. Rev. B, 56 (1997) R8491-R8494

[24] M. Miglierini, and J.M. Greneche. J Phys: Condens Matter. 9 (1997) 2303-2319.

[25] J. Torrens-Serra, P. Bruna, S. Roth, J. Rodriguez-Viejo, and M.T. Clavaguera-Mora, Intermetallics 17 (2009) 79-85.

[26] J.S. Blazquez, A.Conde, and J.M. Greneche, J. Phys.: Condens. Matter 15 (2003) 78437849

[27] Debabrata Mishra, A. Perumal, P. Saravanan, D. Arvindha Babu and A. Srinivasan, J. Magn. Magn. Mater. 321 (2009) 4097-4102

[28] A. Hernando and T. Kulik, Phys. Rev. B. 49 (1994) 7064-7067

[29] X. Liang, J. Ferenc, T. Kulik, A. Slawska-Waniewska, and B. Xu, J. Magn. Magn. Mater. $284(2004) 86-91$ 
[30] K. A. Gallagher, M.A.Willard, V. N. Zabenkin, D.E. Laughlin, and M. McHenry, J. Appl. Phys. 85 (1999) 5130-5132

[31] J. M. Maclaren, T.C. Schulthess, W.H. Butler, R. Sutton, and M. McHenry, J. Appl. Phys. 85 (1999) 4833-4835 


\section{Table and figure captions}

Table 1. Values of the onset temperature $\left(\mathrm{T}_{\mathrm{x} 1}\right)$, enthalpy $\left(\Delta \mathrm{H}_{1}\right)$ and activation energy $\left(\mathrm{E}_{\mathrm{a}}\right)$ for nanocrystallization; values of the peak temperatures for first $\left(T_{p 1}\right)$, second $\left(T_{p 2}\right)$, third $\left(T_{p 3}\right)$ and forth $\left(T_{\mathrm{p} 4}\right)$ crystallization events at heating rate of $10 \mathrm{~K} / \mathrm{min}$.

Table 2. Saturation polarization $\left(\mathrm{J}_{\mathrm{S}}\right)$ and coercivity $\left(\mathrm{H}_{\mathrm{c}}\right)$ for both as-quenched $\left(\mathrm{A}_{\mathrm{A}}\right)$ and nanocrystalline alloys $(\mathrm{N})$, and Curie temperature $\left(\mathrm{T}_{\mathrm{c}}\right)$ and average hyperfine field value $\langle\mathrm{B}\rangle_{\mathrm{A}}$ for as-quenched alloys.

Table 3. Probability (in \%) of finding $\mathrm{n}$ iron atoms surrounding a $\mathrm{Fe}$ atom in a bcc-Fe(Co) structure.

Figure 1 . DSC scans up to $1100 \mathrm{~K}$ of the four alloys at $10 \mathrm{~K} / \mathrm{min}$.

Figure 2. Composition dependence of the nanocrystallization enthalpy $\left(\Delta \mathrm{H}_{1}\right)$; peak temperatures for first $\left(T_{\mathrm{p} 1}\right)$, second $\left(\mathrm{T}_{\mathrm{p} 2}\right)$ crystallization events and Curie temperature of the amorphous phase for our alloys (squares) and data reported by Blazquez [16] (star).

Figure 3. Experimental kinetic function (black continuous line) and Avrami fit (dashed grey line) for Fe77 and Fe69Co8 alloys.

Figure 4. XRD patterns for the four alloys after annealing at $893 \mathrm{~K}$.

Figure 5. Hyperfine field distributions for as-quenched (black squares) and after annealing at $893 \mathrm{~K}$ (grey dots), and $1100 \mathrm{~K}$ (white diamonds) and hyperfine fields of the sextets after annealing at $893 \mathrm{~K}$ (grey bars) and $1100 \mathrm{~K}$ (white patterned bars) for the four alloys.

Figure 6. a) Evolution of the bcc phase percentage after different annealings, b) Evolution of the percentage of $\mathrm{Fe}$ atoms forming part of the different bcc- $\mathrm{Fe}(\mathrm{Co})$ environments after nanocrystallization, and c) Estimation of the amount of Fe atoms in the different crystalline phases after annealing at $1273 \mathrm{~K}$ for all the alloys.

Figure 7. Evolution of the magnetization upon heating for the different alloys.

Figure 8. Compositional dependence of the saturation polarization of both the amorphous and nanocrystalline samples and average hyperfine field of the as-quenched alloys. 
Tables

\begin{tabular}{cccccccc}
\hline & $\mathrm{T}_{\mathrm{x} 1}(\mathrm{~K})$ & $\mathrm{T}_{\mathrm{p} 1}(\mathrm{~K})$ & $\Delta \mathrm{H}_{1}(\mathrm{~J} / \mathrm{g})$ & $\mathrm{E}_{\mathrm{a}}(\mathrm{eV} / \mathrm{at})$ & $\mathrm{T}_{\mathrm{p} 2}(\mathrm{~K})$ & $\mathrm{T}_{\mathrm{p} 3}(\mathrm{~K})$ & $\mathrm{T}_{\mathrm{p} 4}(\mathrm{~K})$ \\
\hline Fe77 & $774 \pm 1$ & $803 \pm 1$ & $35 \pm 3$ & $5.8 \pm 0.1$ & $972 \pm 1$ & $1033 \pm 1$ & $1182 \pm 1$ \\
$\mathrm{Fe} 75 \mathrm{Co} 2$ & $771 \pm 1$ & $803 \pm 1$ & $39 \pm 1$ & $5.3 \pm 0.3$ & $973 \pm 1$ & $1030 \pm 1$ & $1186 \pm 2$ \\
Fe73Co4 & $767 \pm 1$ & $800 \pm 1$ & $43 \pm 1$ & $5.4 \pm 0.1$ & $977 \pm 1$ & $1029 \pm 1$ & $1183 \pm 1$ \\
Fe69Co8 & $756 \pm 1$ & $790 \pm 1$ & $52 \pm 4$ & $5.4 \pm 0.1$ & $984 \pm 1$ & $1034 \pm 1$ & - \\
\hline
\end{tabular}

Table 1

\begin{tabular}{lllllll}
\hline & $\mathrm{J}_{\mathrm{SA}}(\mathrm{T})$ & $\mathrm{J}_{\mathrm{SN}}(\mathrm{T})$ & $\mathrm{H}_{\mathrm{cA}}(\mathrm{A} / \mathrm{m})$ & $\mathrm{H}_{\mathrm{cN}}(\mathrm{A} / \mathrm{m})$ & $\mathrm{T}_{\mathrm{c}}(\mathrm{K})$ & $<\mathrm{B}{ }_{\mathrm{A}}(\mathrm{T})$ \\
\hline Fe77 & $0.81 \pm 0.02$ & $1.17 \pm 0.02$ & $8.5 \pm 0.4$ & $5.8 \pm 0.2$ & $386 \pm 4$ & $13.4 \pm 0.1$ \\
Fe75Co2 & $0.91 \pm 0.01$ & $1.24 \pm 0.01$ & $3.5 \pm 0.5$ & $10.5 \pm 0.5$ & $415 \pm 1$ & $14.9 \pm 0.1$ \\
Fe73Co4 & $0.98 \pm 0.01$ & $1.27 \pm 0.01$ & $9.1 \pm 0.3$ & $19.3 \pm 2.2$ & $436 \pm 1$ & $16.6 \pm 0.5$ \\
Fe69Co8 & $1.07 \pm 0.01$ & $1.30 \pm 0.01$ & $17.6 \pm 0.3$ & $12.8 \pm 0.1$ & $493 \pm 2$ & $18.4 \pm 0.5$ \\
\hline
\end{tabular}

Table 2

\begin{tabular}{lllll}
\hline$n$ & $\mathrm{Fe} 77$ & $\mathrm{Fe} 75 \mathrm{Co} 2$ & $\mathrm{Fe} 73 \mathrm{Co} 4$ & $\mathrm{Fe} 69 \mathrm{Co} 8$ \\
\hline 8 & 100 & 78.86 & 61.74 & 36.96 \\
7 & - & 19.00 & 30.69 & 39.17 \\
6 & - & $<2.0$ & $<7.0$ & 18.17 \\
\hline
\end{tabular}

Table 3 